\title{
A Reliable Protocol for the Isolation of Viable, Chondrogenically Differentiated Human Mesenchymal Stem Cells from High-Density Pellet Cultures
}

\author{
Mujib Ullah,, Houda Hamouda, ${ }^{2}$ Stefan Stich, Michael Sittinger, and Jochen Ringe ${ }^{1}$
}

\begin{abstract}
Administration of chondrogenically differentiated mesenchymal stem cells (MSC) is discussed as a promising approach for the regenerative treatment of injured or diseased cartilage. The high-density pellet culture is the standard culture for chondrogenic differentiation, but cells in pellets secrete extracellular matrix (ECM) that they become entrapped in. Protocols for cell isolation from pellets often result in cell damage and dedifferentiation towards less differentiated MSC. Therefore, our aim was to develop a reliable protocol for the isolation of viable, chondrogenically differentiated MSC from high-density pellet cultures. Human bone marrow MSC were chondrogenically stimulated with transforming growth factor- $\beta 3$, and the cartilaginous structure of the pellets was verified by alcian blue staining of cartilage proteoglycans, antibody staining of cartilage collagen type II, and quantitative real-time reverse-transcription polymerase chain reaction of the marker genes COL2A1 and SOX9. Trypsin and collagenases II and P were tested alone or in combination, and for different concentrations and times, to find a protocol for optimized pellet digestion. Whereas trypsin was not able to release viable cells, 90-min digestion with $300 \mathrm{U}$ of collagenase II, $20 \mathrm{U}$ of collagenase $\mathrm{P}$, and $2 \mathrm{mM} \mathrm{CaCl}_{2}$ worked quite well and resulted in about $2.5 \times 10^{5}$ cells/pellet. The protocol was further optimized for the separation of released cells and ECM from each other. Cells were alcian blue and collagen type II positive and expressed COL2A1 and SOX9, verifying a chondrogenic character. However, they had different morphological shapes. The ECM was also uniformly alcian blue and collagen type II positive but showed different organizational and structural forms. To conclude, our protocol allows the reliable isolation of a defined number of viable, chondrogenically differentiated MSC from high-density pellet cultures. Such cells, as well as the ECM components, are of interest as research tools and for cartilage tissue engineering.
\end{abstract}

Key words: cell isolation; chondrogenic differentiation; enzymatic pellet digestion; extracellular matrix

\section{Introduction}

$\mathbf{H}$ YALINE CARTILAGE NOT ONLY PLAYS an integral role in the skeletal framework of the body but also coats the surfaces of bones in joints to facilitate bone gliding and to prevent bone abrasion. ${ }^{1,2}$ In general, cartilage consists of chondrocytes and extracellular matrix (ECM), and both components work in an interdependent manner to maintain structure and function., ${ }^{3,4}$ Cartilage disorders due to injury or disease not only disturb this structural organization but also affect the functional ability of this tissue. ${ }^{5,6}$ It is known that cartilage has a limited ability for self-repair due to its lack of vascular supply, lymphatic drainage, and innervations. Moreover, chondrocytes are entrapped in their ECM and thus have no physical contact with each other and restricted migration potential to defect sites. ${ }^{2,3,7}$ For these reasons, cartilage disorders often result in destruction of hyaline joints and require joint arthroplasty.

Today, for the regenerative treatment of cartilage lesions, autologous chondrocytes are routinely clinically applied as a cell suspension (ACI), a high-density pellet of cells and ECM, or in combination with matrices (MACI). ${ }^{8-10}$ However, problems arise when chondrocytes are cultured because the propagation to achieve sufficient cell numbers is accompanied by chondrocyte senescence ${ }^{11,12}$ and dedifferentiation of round cells to fibroblast-like cells with decreased cartilage formation capacity. ${ }^{13,14}$ Three-dimensional (3D) culture reduces but does not overcome the problem. In general, chondrocyte-

\footnotetext{
${ }^{1}$ Tissue Engineering Laboratory and Berlin-Brandenburg Center for Regenerative Therapies, Department of Rheumatology and Clinical Immunology; ${ }^{2} \mathrm{AG}$ Glycodesign and Glycoanalytics, Institute of Laboratory Medicine, Clinical Chemistry, and Pathobiochemistry; CharitéUniversitätsmedizin Berlin, Berlin, Germany.
} 
based techniques do not result in native cartilage but rather pain relief, formation of hyaline and/or inferior fibrocartilage, and a delay of joint destruction.

Mesenchymal stem cells (MSC), or multipotent mesenchymal stromal cells, are discussed as an alternative cell source. ${ }^{13-16}$ Because they are easy to isolate and to expand and can differentiate into cartilage, migrate to diseased organs, and secrete molecules enabling their allogeneic use as a kind of controlled factor delivery system, MSC are promising cells for cartilage tissue engineering. ${ }^{10,17}$ Today, for the regenerative treatment of injured or diseased cartilage, bone marrow-stimulating techniques like microfracture, combined with supporting matrices, are routinely applied in situ to recruit MSC to cartilage defect sites. ${ }^{18,19}$ Results are similar to ACI and MACI. However, no cell product based on administration of differentiated or undifferentiated MSC exists.

The 3D high-density pellet culture is the standard assay for chondrogenesis in vitro. ${ }^{15,20}$ Here, a loose, spherical MSC pellet is chondrogenically induced by the addition of the standard stimulus, transforming growth factor (TGF) $\beta$, leading to a firm, spherical MSC pellet resembling hyaline cartilage and consisting of differentiated MSC and their ECM. The ECM mostly consists of different proteoglycans and collagens, which are usually cross-linked and provide a protective cage in which the TGF $\beta$-stimulated MSC are entrapped. $^{21-23}$ So, the isolation of these cells from their ECM is a challenging task, but is the prerequisite to deliver viable, chondrogenically differentiated MSC. To our knowledge, no successful procedure for the isolation of such cells from pellets has been published.

Herein, we present a protocol for isolation of viable, chondrogenically differentiated human MSC from high-density pellet cultures for research and regenerative applications. ${ }^{24,25}$ This reliable and easy-to-use protocol, based on an enzymatic cocktail of collagenase II, collagenase $\mathrm{P}$, and $\mathrm{CaCl}_{2}$, results in about $2.5 \times 10^{5}$ cells per pellet and maintains the chondrogenically differentiated state of these cells. This is shown with cell-culture techniques, histological and immunohistochemical staining and quantitative real-time reversetranscription polymerase chain reaction (qPCR). As a byproduct, cartilage ECM components, often discussed as growth and differentiation factors, are enriched and can be used in research.

\section{Material and Methods}

\section{Isolation and culture propagation of human MSC}

Human MSC were isolated from bone marrow aspirates of the iliac crest of three informed, consenting donors $(n=3$, average age: $68 \pm 4.6$ years) who were examined to exclude hematopoietic neoplasms; samples were found to be histologically normal. The local ethical committee of the CharitéUniversitätsmedizin Berlin approved the study. Nucleated cells in the aspirates were counted and suspended in culture medium consisting of Dulbecco's modified Eagle's medium (DMEM; Biochrom), 10\% fetal bovine serum (Thermo Scientific Hyclone), $2 \mathrm{ng} / \mathrm{mL}$ basic fibroblast growth factor (FGF; PeproTech), $10 \mathrm{mM}$ HEPES buffer, $4 \mathrm{mM}$ L-glutamine, $100 \mathrm{U} / \mathrm{mL}$ penicillin, and $100 \mu \mathrm{g} / \mathrm{mL}$ streptomycin (all Biochrom). Cells were seeded at a density of $2 \times 10^{5}$ cells $/ \mathrm{cm}^{2}$. After $72 \mathrm{~h}$, nonadherent cells and debris were washed out by the first media exchange. Then, medium was exchanged three times a week and cells were detached after $90 \%$ confluence with $0.05 \%$ trypsin $/ 1 \mathrm{mM}$ EDTA (both Biochrom), subcultured (seeding density: $5 \times 10^{3}$ cells $/ \mathrm{cm}^{2}$ ), and expanded until passage 3 (P3).

\section{Flow cytometric analysis of human MSC}

To verify their presentation of MSC marker, P3 MSC of all donors were analyzed using a FACSCalibur flow cytometer (Becton Dickinson). Briefly, cells were collected and suspensions of $2.5 \times 10^{5}$ cells were washed with phosphate-buffered saline (PBS) $/ 0.5 \%$ bovine serum albumin (BSA; both Biochrom). For direct staining, cells were centrifuged (250 $g$, $5 \mathrm{~min}$ ) and resuspended in cold PBS $/ 0.5 \%$ BSA. Afterwards they were incubated for $15 \mathrm{~min}$ on ice with titrated concentrations of R-phycoerythrin-labeled mouse anti-human CD14, CD34, CD73, CD166, fluorescein isothiocynate (FITC)-labeled mouse anti-human CD44, CD45, CD90 (all BD Pharmingen), or FITC-labeled mouse anti-human CD105 (Acris Antibodies). Finally the cells were washed in cold PBS $/ 0.5 \%$ BSA and resuspended in the same buffer before flow cytometric analysis. Propidium iodide $(100 \mu \mathrm{g} / \mathrm{mL}$; Sigma-Aldrich) staining was applied to exclude dead cells and debris, while unstained cells were used as a negative control. Data were evaluated using CellQuest software (Becton Dickinson).

\section{Chondrogenic differentiation of human MSC}

For chondrogenic differentiation in high-density pellet cultures ( $n=6$ donors, P3), $2.5 \times 10^{5}$ MSC were centrifuged $(150 \mathrm{~g}$, $5 \mathrm{~min}$ ) in a $15-\mathrm{mL}$ polypropylene tube (Becton Dickinson) to form a pellet. The pellets were treated for 28 days with defined serum-free chondrogenic medium, which consisted of DMEM (4.5 g/L glucose; Biochrom), ITS + 1 supplement, $100 \mathrm{nM}$ dexamethasone, $0.17 \mathrm{mM}$ L-ascorbic acid-2-phosphate, $1 \mathrm{mM}$ sodium pyruvate, $0.35 \mathrm{mM}$ L-prolin (all SigmaAldrich), and $10 \mathrm{ng} / \mathrm{mL}$ TGF $\beta 3$ (R\&D Systems). Control pellets were cultured in the same medium without TGF $\beta 3$. Medium was changed three times a week.

\section{Establishment of an appropriate protocol for cell isolation from pellet cultures}

To isolate viable, chondrogenically differentiated MSC from entrapped ECM, we established a step-by-step protocol. High-density pellets were digested by using six different approaches. In the first approach, pellets were incubated with $0.05 \%$ trypsin $/ 1 \mathrm{mM}$ EDTA for 10,20 , and $30 \mathrm{~min}$ at $37^{\circ} \mathrm{C}$ and $5 \% \mathrm{CO}_{2}$. In the second approach, they were cut into small pieces with a sharp blade and then incubated with $0.05 \%$ trypsin/ $1 \mathrm{mM}$ EDTA for 10,20 , and $30 \mathrm{~min}$. In the third approach, they were incubated for 60 and $120 \mathrm{~min}$ with 100, 200, and $300 \mathrm{U}$ of collagenase II (Biochrom), and in the fourth approach for the same time with 10, 20, and $30 \mathrm{U}$ of collagenase $\mathrm{P}$ (Roche). In the fifth approach, $300 \mathrm{U}$ of collagenase II and $20 \mathrm{U}$ of collagenase P were mixed and the mixture was incubated for 30,60,90, and $120 \mathrm{~min}$. Finally, in the sixth approach, $2 \mathrm{mM} \mathrm{CaCl}_{2}$ was added to the fifth approach mixture, which was then incubated for 90 and $120 \mathrm{~min}$ at $37^{\circ} \mathrm{C}$ and $5 \% \mathrm{CO}_{2}$ to digest pellet cultures. As presented in the Results, the last approach $(90 \mathrm{~min})$ was best. 


\section{Isolation of viable, chondrogenically differentiated human MSC from pellet cultures}

The newly established protocol was applied in all further studies. Initially, medium was removed and the pellet culture was washed with PBS. Then, for enzymatic digestion, the pellet was digested with $300 \mathrm{U}$ of collagenase II, $20 \mathrm{U}$ of collagenase $\mathrm{P}$, and $2 \mathrm{mM} \mathrm{CaCl}_{2}$ for $90 \mathrm{~min}$ at $37^{\circ} \mathrm{C}$ and $5 \% \mathrm{CO}_{2}$. This resulted in a mixture of viable, chondrogenically differentiated cells, ECM, semidigested pellets, enzymes, and debris. Based on our targeted cell number, mixtures were isolated from 25 pellets (about $2.0 \times 10^{5}$ cells/pellet) per donor $(n=3)$, pooled, and then mechanically homogenized by gentle pipetting to dislodge and release the cells from ECM.

\section{Isolation of ECM and its enrichment}

To isolate ECM, the whole digested extract consisting of cells, ECM, enzymes, and debris was transferred to a $50-\mathrm{mL}$ tube and centrifuged at $350 \mathrm{~g}$ for $6 \mathrm{~min}$. Then supernatant was discarded, and the precipitate was resuspended in culture medium supplemented with TGF $\beta 3$. We added this chondrogenic stimulus to maintain the differentiated state of chondrogenically differentiated cells and to exclude cell dedifferentiation. Subsequently, cells along with ECM and other debris were transferred to a culture flask and incubated at $37^{\circ} \mathrm{C}$ and $5 \% \mathrm{CO}_{2}$. After $2 \mathrm{~h}$, viable, chondrogenic cells were attached to the culture surface, while the ECM, dead cells, and cellular debris remained unattached. The nonadherent substances were removed by medium exchange and centrifuged at $350 \mathrm{~g}$ for $6 \mathrm{~min}$ at $37^{\circ} \mathrm{C}$. The process of medium removal and centrifugation was repeated three times to ensure the maximum removal of ECM for its enrichment. Cells and ECM were used separately for histological, immunohistochemical, and gene expression analysis.

\section{Histological and immunohistochemical analysis}

To demonstrate chondrogenesis, high-density pellet cultures were embedded in Tissue-Tek O.C.T. compound (Sakura Finetek), frozen in liquid nitrogen and cryosectioned ( $6 \mu \mathrm{m}$ thickness). To analyze the secretion of cartilage proteoglycans, sections were stained with alcian blue 8GS (Roth) and counterstained with nuclear fast red (Sigma-Aldrich). For immunohistochemical analysis of collagen type II formation, sections were incubated for $1 \mathrm{~h}$ with a primary rabbit anti-human collagen type II antibody (Acris Antibodies), processed with the EnVision system peroxidase kit (DAKO), and counterstained with hematoxylin (Merck).

For histological and immunohistochemical analysis of viable, chondrogenic cells, four-well chamber slides were used (Thermo Scientific). For alcian blue and collagen type II staining, $2.0 \times 10^{5}$ chondrogenically differentiated cells were transferred to each well. Slides were then incubated at $37^{\circ} \mathrm{C}$ and $5 \% \mathrm{CO}_{2}$ for 4 days. Then, for direct staining the medium was removed, and cells were washed with PBS and fixed for $5 \mathrm{~min}$ in cooled $3.7 \%$ formaldehyde in PBS. Finally, cells were stained according to the protocols already described for cryosections.

\section{Isolation of RNA from high-density pellet cultures and $q P C R$}

For qPCR analysis of high-density pellet cultures and viable, chondrogenically differentiated cells, total RNA was harvested. For pellet RNA extraction, pellets were pooled for each individual donor ( $n=3,14$ pellets for each donor), mixed with TriReagent (Sigma-Aldrich), and mechanically homogenized with an Ultra-Turrax (IKA). For RNA extraction from monolayer cells ( $n=3$ donors), mechanical homogenization was not necessary; 1-bromo-3-chloro-propane (Sigma-Aldrich) was added followed by centrifugation $(13,000 \mathrm{~g}, 45 \mathrm{~min})$. The aqueous phase was collected and mixed with an equal amount of ethanol. Further steps were performed applying the RNeasy Mini Kit (Qiagen). Finally, RNA quality and quantity were measured with the NanoDrop (NanoDrop products).

For qPCR, cDNA was synthesized from total RNA $(2.5 \mu \mathrm{g})$ with the iScript cDNA synthesis kit (BioRad). Then, TaqMan qPCR was performed in triplicate in 96-well optical plates on a Mastercycler ${ }^{\circledR}$ ep realplex2 S system (Eppendorf) with gene expression assays for TaqMan probes and primer sets (Applied Biosystems). Quantitative gene expression was analyzed for the chondrogenic marker genes collagen type 2 A1 (COL2A1; assay ID: Hs00264051_m1) and SRY (sex determining region Y)-box-9 (SOX9; Hs00165814_m1) and for the housekeeping gene glyceraldehyde-3-phosphate dehydrogenase (GAPDH; Hs99999905_m1). COL2A1 and SOX9 expression was normalized to the endogenous GAPDH expression level and calculated with the $2^{-\Delta \Delta C t}$ formula as percentage of GAPDH expression. ${ }^{26}$

\section{Statistical analysis}

Statistical analysis was performed using SigmaStat 3.5 (Systat), while GraphPad Prism4 (GraphPad) was applied to draw graphs. Students' $t$-test was applied for nonparametric quantitative data sets analysis and one tailed $p$-values were calculated; $p<0.05$ and $p<0.001$ were considered to be statistically significant. Error bars in all figures represent the standard error of the mean (SEM).

\section{Results}

\section{Isolation and culture of human MSC}

MSC were isolated from human bone marrow aspirates of three donors and subsequently culture expanded up to P3. In P0, cells showed the typical fibroblast-like morphology of primary MSC (Fig. 1A). During culture propagation up to P3, cells were slightly flattened but still showed a homogeneous fibroblast-like morphology (Fig. 1B). In P3, flow cytometric analysis was performed to verify if the cells had the standard MSC surface marker profile. As expected, MSC were uniformly positive for CD44, CD73, CD90, CD105, and CD166 and negative for the hematopoietic markers CD14, CD34, and CD45 (Fig. 1C). We and others have shown the multilineage differentiation potential of such cells in many studies; here we were only interested in their chondrogenic differentiation potential.

\section{Chondrogenic differentiation of MSC in high-density pellet cultures}

MSC were chondrogenically stimulated with TGF $\beta 3$ in the standard pellet culture assay. After initial centrifugation in 15-mL polypropylene tubes, MSC settled and formed loose, spherical pellets. During the first week, pellets started to increase in size and had a thinner central zone as compared 

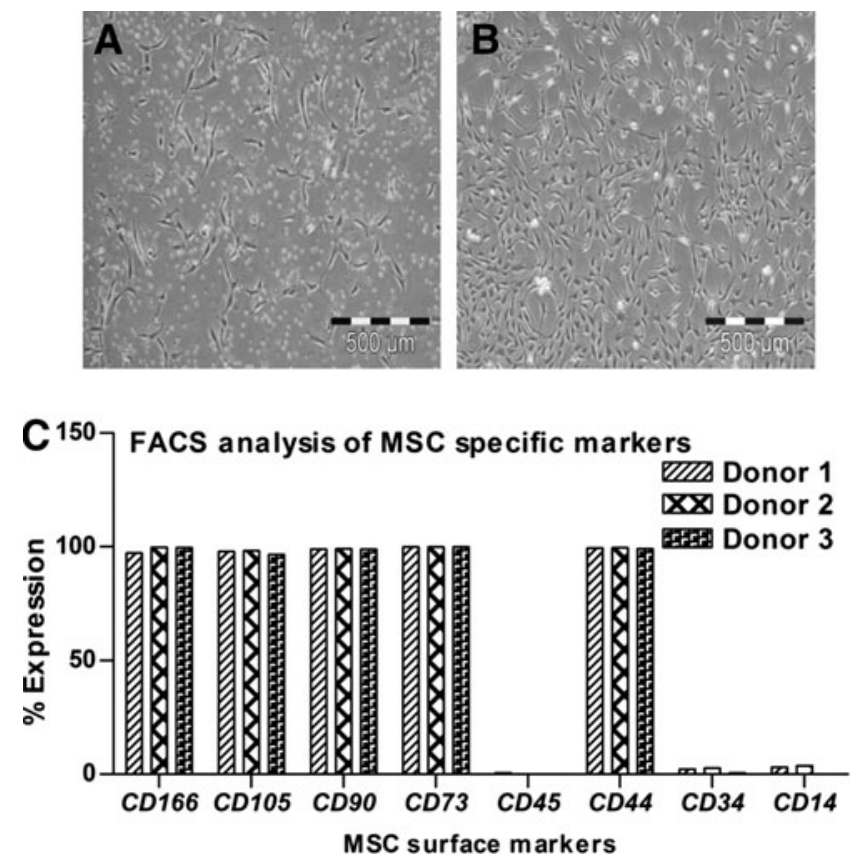

FIG. 1. (A) During isolation, human bone marrow mesenchymal stem cells (MSCs) appeared as single cells in passage 0 (P0), (B) then they showed uniform growth and fibroblast like morphology in P3. (C) On FACS analysis the cells were positive for typical MSC antigens like CD166, CD105, CD90, CD73, and CD44, while negative for hematopoietic lineage-specific antigens like CD45, CD34, and CD14. Bar: $500 \mu \mathrm{m}$.

to a thicker circumferential border. After 28 days, pellets were converted into firm, mechanically strong cultures (Fig. 2). At that point, alcian blue staining of cartilage proteoglycans (Fig. 2A) and antibody staining of cartilage-specific collagen type II (Fig. 2C) revealed the formation of a cartilaginous ECM. Both alcian blue (Fig. 2B) and collagen type II (Fig. 2D) staining were negative in unstimulated pellet cultures. On the gene expression level, chondrogenesis was measured by significantly increased expression of the cartilage marker genes SOX9 and COL2A1 from day 0 to day 28 (Fig. 2E). Both genes were also much more highly expressed in stimulated cultures than in unstimulated cultures (Fig. 2E).

\section{Establishment of a protocol to isolate viable, chondrogenically differentiated MSC}

The isolation of viable, chondrogenically differentiated cells from high-density pellet cultures was a challenging task because they were entrapped in the firm, mechanically strong ECM, and no appropriate protocol was known. Testing different approaches, we established a step-by-step procedure for the enzymatic release of cells from such cultures. The first approach was based on the knowledge that trypsin is the standard enzyme to release viable cells from a broad spectrum of tissues. So, pellets were incubated under standard cell culture conditions with $0.05 \%$ trypsin/ $1 \mathrm{mM}$ EDTA for 10,20 , and $30 \mathrm{~min}$. However, according to trypan blue staining of cells and subsequent counting by hemocytometer, no viable or dead cells were released (Fig. 3A). We assumed that due to the presence of a protective ECM layer on the pel-
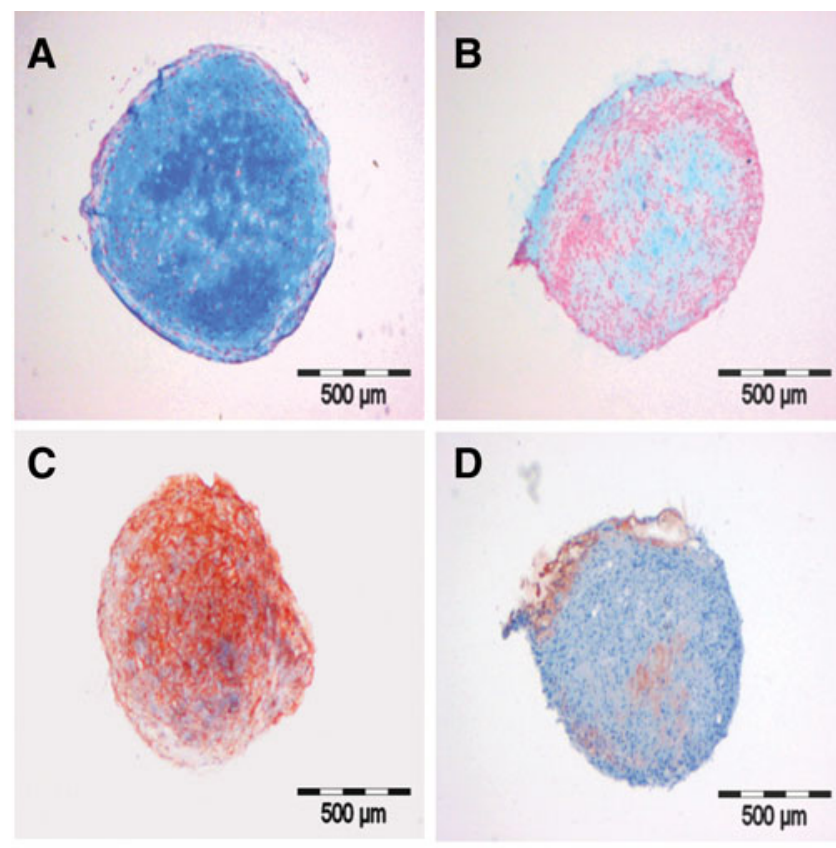

D

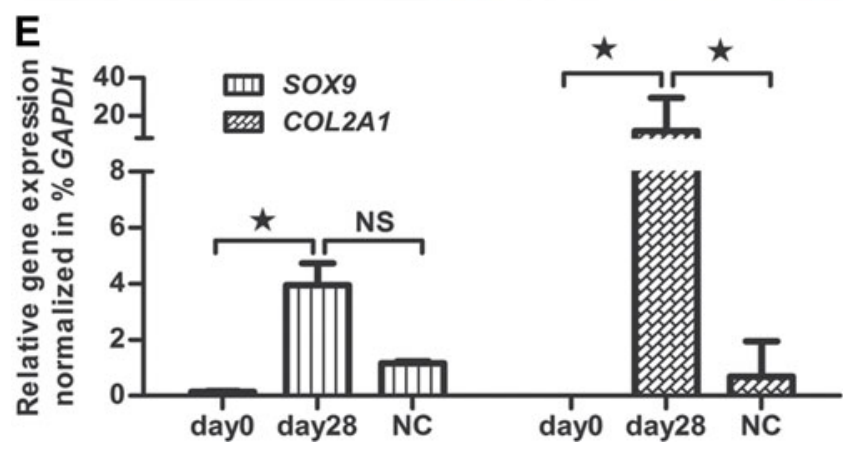

FIG. 2. MSC were induced to chondrogenic lineage cells. Their chondrogenic ability was assessed via (A) alcian blue and $(\mathrm{C})$ collagen type II staining, while the controls were negative for both (B) alcian blue and (D) collagen type II staining. (E) After 28 days of induction, the chondrogenic MSC showed significant expression of cartilage-specific genes SOX9 and COL2A1 as compared to negative controls (NC) and undifferentiated MSC, day 0. Bar: $500 \mu \mathrm{m}$.

let surface, trypsin was not able to release any cells. Therefore, in the second approach, each pellet was cut into small pieces with a sharp blade; incubated with $0.05 \%$ trypsin $/ 1 \mathrm{mM}$ EDTA for 10, 20, and $30 \mathrm{~min}$; and then mechanically dislodged to release the cells by pipetting. Obviously, some viable cells were released (Fig. 3B) but compared to the number of dead cells, after 10-min (Fig. 3C, D), 20-min (Fig. 3E, F), and 30-min (Fig. 3G, H) incubation, their number was very low. Moreover, the majority of the few viable cells were unable to proliferate and most of them died after 1 day in subsequent cell culture (data not shown). Based on these results, trypsin was excluded from our study. In the third approach, 100, 200, and $300 \mathrm{U}$ of collagenase II (Fig. 4A) and in the fourth approach, 10, 20, and $30 \mathrm{U}$ of collagenase $\mathrm{P}$ (Fig. 4B) were used in 60- and 120-min incubations under standard cell culture conditions. This was based on the knowledge that the ECM contains diverse collagens, among which collagen type II is 

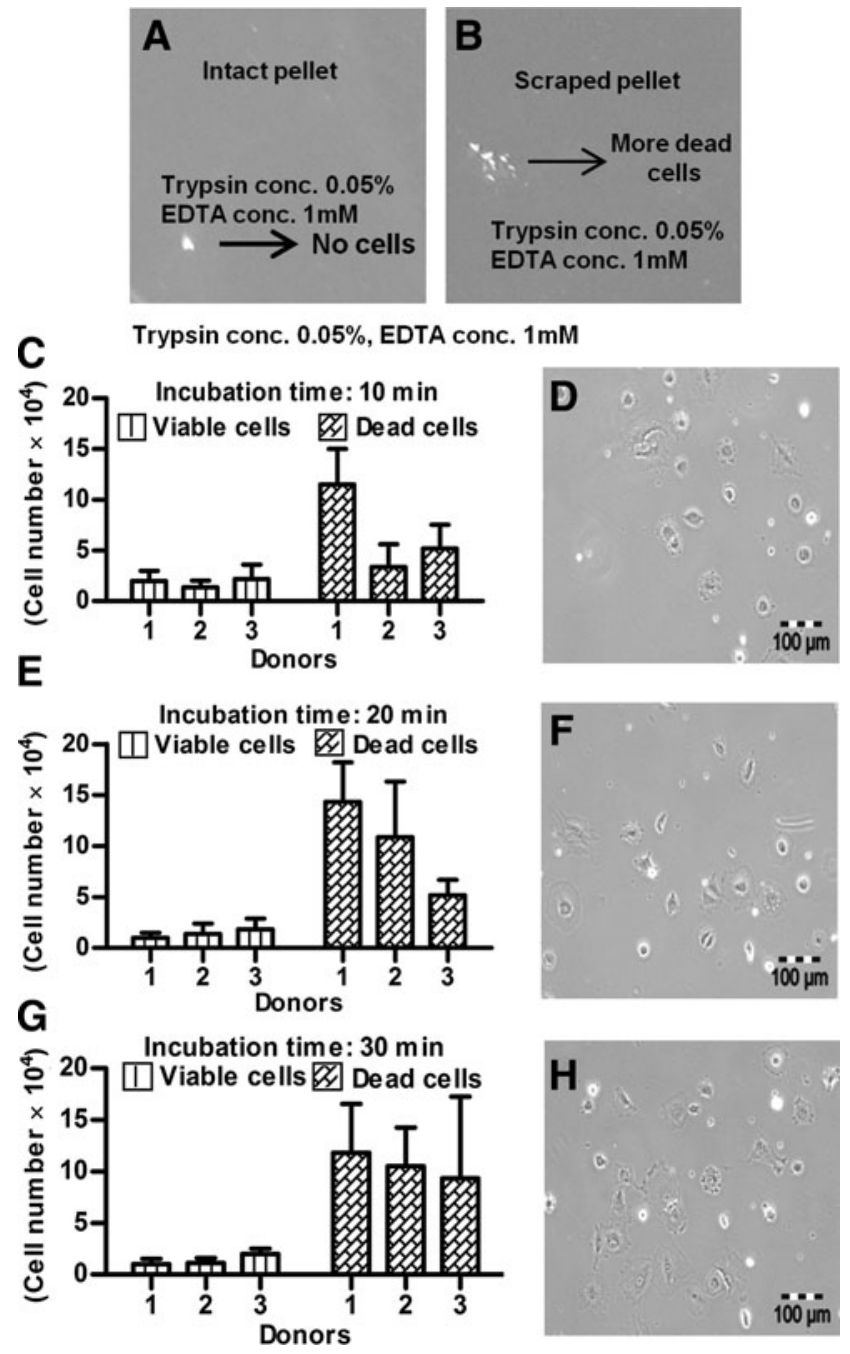

FIG. 3. (A) Incubation of intact pellets with trypsin did not release any cells, (B) while incubation with trypsin of pieces scraped from pellets released cells, the majority of which were dead. The numbers of released cells from the scraped pieces are shown after $10 \mathrm{~min}$ (C) with corresponding morphology (D); after $20 \mathrm{~min}$ (E) with corresponding morphology (F); and after $30 \mathrm{~min}(\mathrm{G})$ with corresponding morphology (H). Bar: $100 \mu \mathrm{m}$.

prominent. After 60 and $120 \mathrm{~min}, 300 \mathrm{U}$ of collagenase II resulted in the highest number of viable, released cells (Fig. 4A). For collagenase $P$, results were ambiguous (Fig. 4B) and the amount of released cells was lower than in the collagenase II approach. In the fifth approach, $300 \mathrm{U}$ of collagenase II and $20 \mathrm{U}$ of collagenase P were combined together for 30 - to 120-min incubations. The resultant semidigested pellets were mechanical dislodged by gentle pipetting. After the 30-min incubation, roughly $1.5 \times 10^{4}$ viable cells per pellet were released (Fig. 4C) and showed normal morphology (Fig. 4E). However, the number of nonviable cell was relatively high, and some cells remained as small clumps in the ECM (Fig. 4C,E). After $60 \mathrm{~min}$, the number of released, viable cells was increased, and the other characteristics were constant (Fig. 4D, F). Thirty minutes later, the number of viable cells was further increased (roughly $2.8 \times 10^{4}$ cells/pellet; Fig. 4G), the morphology was slightly flattened, and the num- ber of clumps was decreased (Fig. 4I). After $120 \mathrm{~min}$, with about $3.0 \times 10^{4}$ cells/pellet, the highest number of viable cells was released from the pellet cultures (Fig. $4 \mathrm{H}$ ), but most of them died in subsequent culture, and the remaining cells became more flattened and showed almost no proliferation (Fig. 4J). We assumed that cell damage was correlated with an increased incubation time in the enzymatic cocktail; therefore, to reduce this time, we added $\mathrm{CaCl}_{2}$ in the last approach. Calcium chloride is considered to be a stabilizing agent for diverse collagenases and increases their activity. ${ }^{27,28}$ Pellets were incubated in $300 \mathrm{U}$ of collagenase II, $20 \mathrm{U}$ of collagenase $\mathrm{P}$, and $2 \mathrm{mM} \mathrm{CaCl}{ }_{2}$ at $37^{\circ} \mathrm{C}$ and $5 \% \mathrm{CO}_{2}$ for 90 and $120 \mathrm{~min}$. As expected, at $90 \mathrm{~min}, \mathrm{CaCl}_{2}$ supplementation resulted in a very high number of released cells (about $3.9 \times 10^{4}$ cells/pellet) (Fig. 5A). These cells were morphologically normal and proliferated in subsequent culture (Fig. 5C). After $120 \mathrm{~min}$, we did not observe any further increase in the amount of released, viable cells (Fig. 5B), and there were more dead cells (Fig. 5D). In conclusion, $300 \mathrm{U}$ of collagenase II, $20 \mathrm{U}$ of collagenase $\mathrm{P}$, and $2 \mathrm{mM} \mathrm{CaCl}_{2}$ were used in our protocol for $90 \mathrm{~min}$ at $37^{\circ} \mathrm{C}$ and $5 \% \mathrm{CO}_{2}$. The protocol was then further optimized for the separation of released cells and ECM from each other (Materials and Methods) and resulted in about $2.5 \times 10^{5}$ cells per pellet.

\section{Morphology and chondrogenic character of isolated cells}

The culture appearance of viable, chondrogenically differentiated cells was inhomogeneous. We observed groups of cells that were different in size from small (Fig. 6A) to large (Fig. 6B), in shape from spherical (Fig. 6A) to polygonal (Fig. 6B), and in appearance from individual (Fig. 6A) to grouped (Fig. 6B). Some had flatted ends compared to others (Fig. 6C), with distinct nucleus and abundant cytoplasm (Fig. 6C,D). Clearly, most had a tri- or multi-angular morphology (Fig. 6D). However, during isolation cells retained their chondrogenic character, as shown by positive alcian blue (Fig. 7A) and collagen type II (Fig. 7C) staining. Cells isolated from unstimulated negative control pellets were alcian blue (Fig. 7B) and collagen type II negative (Fig. 7D). Cells were also cross-checked on the gene level for expression of SOX9 and COL2A1. The expression of both marker genes in percent expression of $G A P D H$ in cultures with cells released from chondrogenically stimulated pellets was significantly higher than in cultures with cells released from unstimulated control pellets (Fig. 7E).

\section{Extracellular matrix}

After separation of released cells and ECM from each other, we further analyzed the ECM-enriched fraction, which contained some debris, that did not attach to the culture surface during separation. In morphological evaluation, we observed two main structures (Fig. 8), a small particle-like structure (Fig. 8A) and an almost uniform, small membranelike structure (Fig. 8B). The chondrogenic characteristic of these two ECM structures was examined by alcian blue and collagen type II staining. Alcian blue staining confirmed the presence of cartilage proteoglycans in both morphological structures (Fig. 8C, D). However, the intensity was higher in the group with particle-like structures (Fig. 8C). Counterstaining with nuclear fast red was negative, indicating that no cells were in the ECM fraction. Both structures were 
A

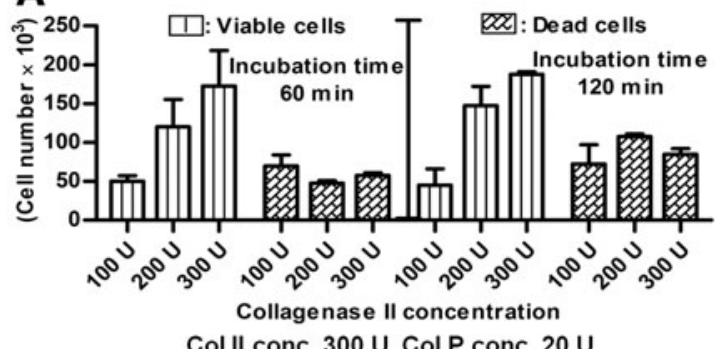

C
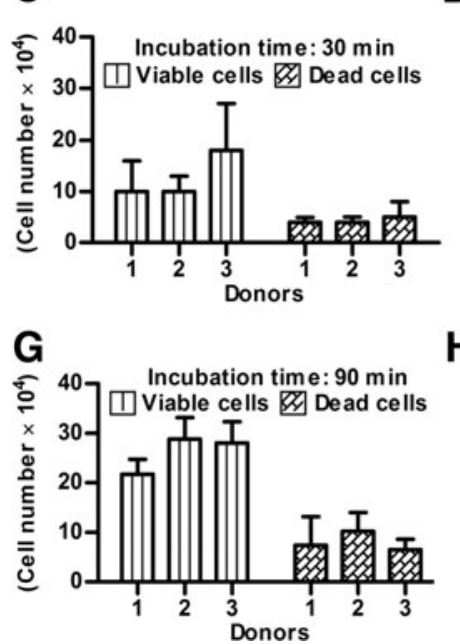

D

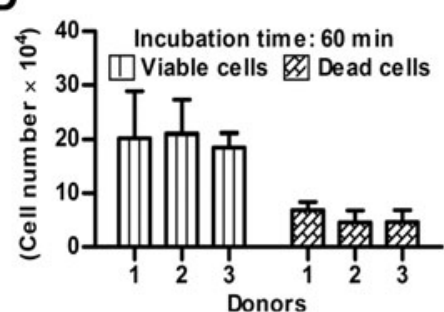

H

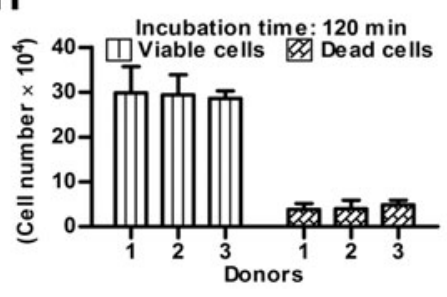

B
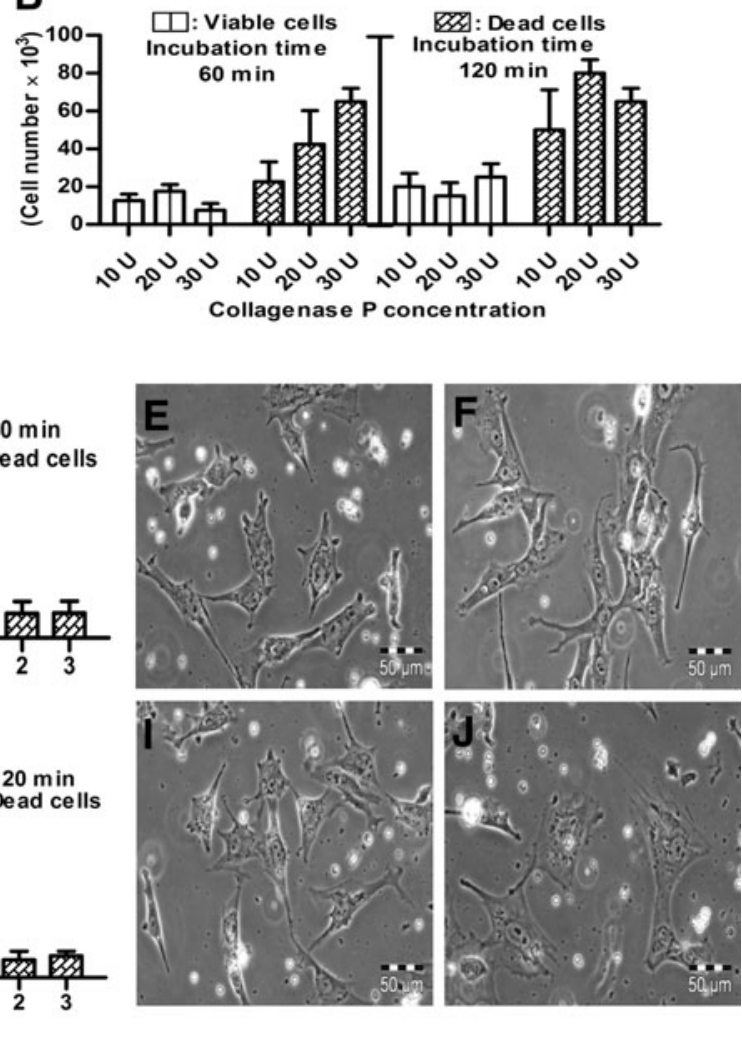

FIG. 4. The chondrogenic intact pellets were digested with (A) collagenase II and (B) collagenase P for different time points on individual bases. Then $300 \mathrm{U}$ of collagenase II and $20 \mathrm{U}$ of collagenase $\mathrm{P}$ were combined together and added to the intact pellets. The cell numbers released upon digestion are shown after (C) $30 \mathrm{~min}$, (D) $60 \mathrm{~min}$, (G) $90 \mathrm{~min}$, and (H) $120 \mathrm{~min}$ incubation time point. Their corresponding morphology is given after enzymatic digestion of (E) $30 \mathrm{~min}$, (F) $60 \mathrm{~min}$, (I) $90 \mathrm{~min}$ and (J) 120 min. Bar: $50 \mu \mathrm{m}$.

collagen type II positive (Fig. 8E, F), with a higher intensity in the membranous-like structure. As shown exemplarily in Fig. 8D and 8F, ECM from unstimulated control pellets was both alcian blue and collagen type II negative.

\section{Discussion}

For the regenerative treatment of injured or damaged articular cartilage, chondrogenically differentiated MSC, isolated from diverse tissues with or without matrices, are considered a promising alternative for autologous chondrocytes transplantation. ${ }^{13,25,29}$ In this context the high-density pellet culture represents a model system to provide a large amount of chondrogenic MSC, ${ }^{15,20}$ especially when such cells should be applied as a suspension for regenerative application. However, inside intact pellet culture, the cells and their secreted ECM components enclose and fix each other, ${ }^{1-3}$ hindering the release of chondrogenic MSC. This emphasizes the need for a successful protocol to isolate cells from pellets, despite an array of published protocols for chondrocyte isolation from native cartilage. ${ }^{30,31}$ Unfortunately, such protocols are not applicable to isolating viable cells from pellets, and we believed that appropriate pellet digestion represented the key step to achieve this. We thus examined the parameters of enzyme selection, concentration, and incubation time to establish uniform standards for the reproducible release of viable cells from high-density pellet cultures.
First, MSC were chondrogenically stimulated with TGF $\beta 3$ for 28 days to generate high-density pellet cultures. The chondrogenic nature of these pellets was verified by histochemical examination of cartilage proteoglycan, antibody staining of cartilage collagen type II, and qPCR of COL2A1 and SOX9.

Then, to start pellet digestion, trypsin was applied because it is broadly accepted as the enzyme for release of cells from culture surfaces and diverse native tissues. Initially trypsin did not release any cells from intact whole pellets, and very few cells were released from small pieces of knife-scraped pellets. In line with these results, trypsin was previously found to be insufficient to isolate chondrocytes from cartilage. ${ }^{30}$ Since cartilage and chondrogenic pellet cultures contain a huge amount of collagen, collagenases are important digestion enzymes. We and others have used a mixture of collagenase II and collagenase $P$ to isolate chondrocytes from normal and osteoarthritic cartilage. ${ }^{30,32,33}$ Therefore, we next tested these two enzymes alone or in combination, and found a mixture of $300 \mathrm{U}$ of collagenase II and $20 \mathrm{U}$ of collagenase P optimum at 90 and $120 \mathrm{~min}$ of incubation for maximum release of viable cells. But most cells either died on subsequent culturing or otherwise showed low proliferation rate. Since digestion of native cartilage with these enzymes is often performed overnight, we did not expect such a negative influence with our incubation times, ${ }^{30,32,33}$ especially with our selected enzyme concentration being in the standard range. This implies differences between the structure of native 


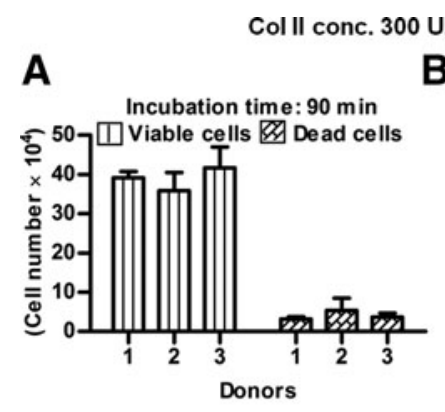

B
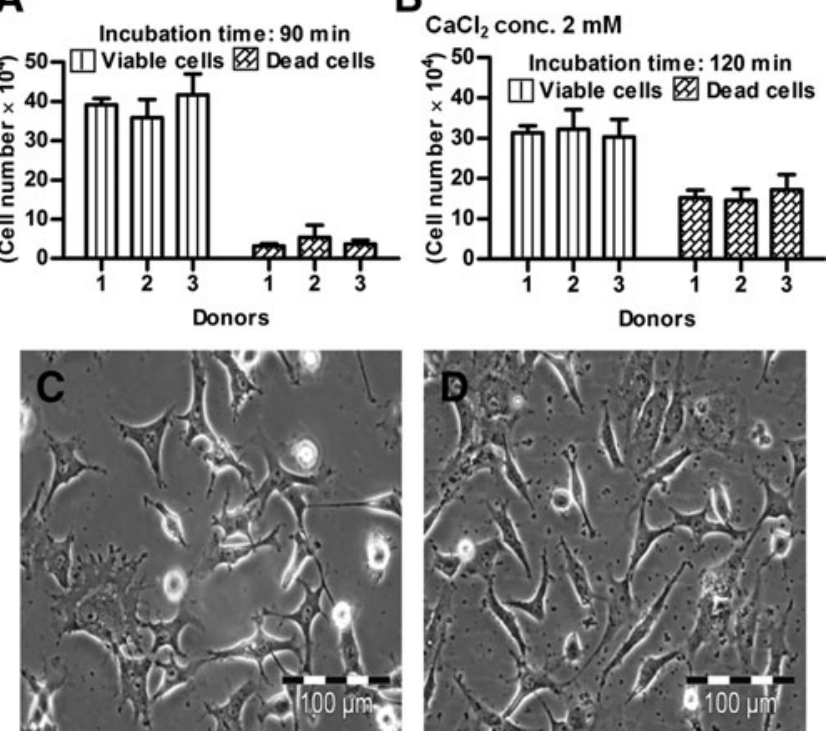

FIG. 5. The chondrogenic intact pellets were digested with collagenase II ( $\mathrm{Col}$ II) and collagenase $\mathrm{P}(\mathrm{Col} \mathrm{P})$ in presence of $\mathrm{CaCl}_{2}$ for different time points. The released cell numbers are shown after (A) 90-min and (B) 120-min incubation. Similarly their morphology is given after (C) 90-min and (D) 120-min enzymatic digestion. Bar: $100 \mu \mathrm{m}$.

cartilage and pellet culture cartilage. Since it is known that $\mathrm{CaCl}_{2}$ stabilizes several collagenases and increases their activity, thus accelerating the digestion process, we added it to our enzymatic cocktail. ${ }^{27,28}$ After $90 \mathrm{~min}$, with about $3.9 \times 10^{4}$ cells / pellet, this addition resulted in a highly increased num-
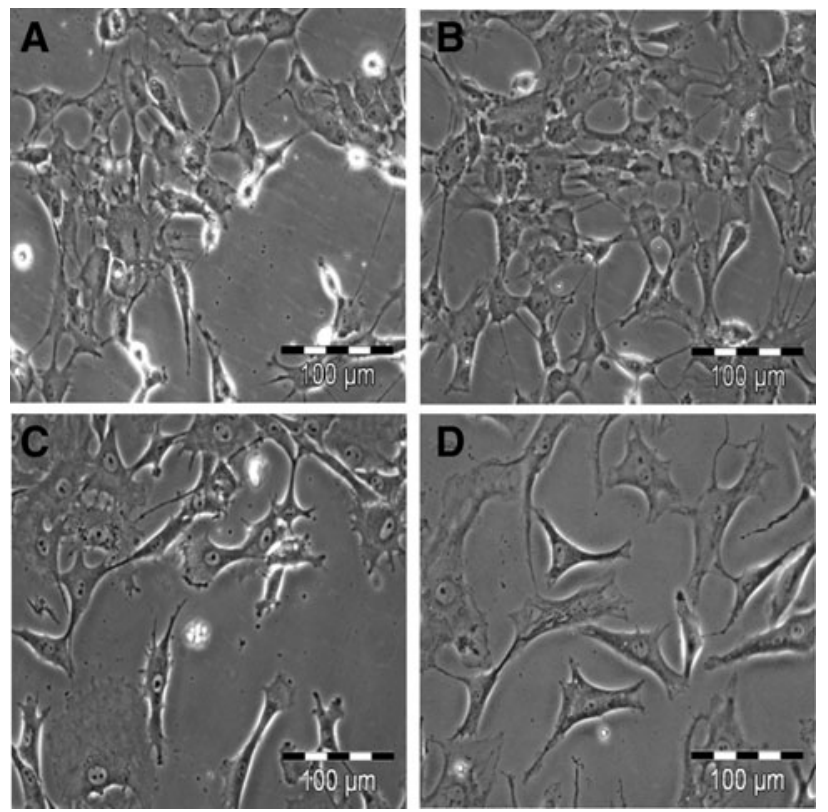

FIG. 6. The released cells were purified from the components of ECM, which showed different morphology such as being (A) small in size and spherical in shape, (B) large in size and polygonal in shape, (C) large in size and longitudinal in shape with one flattened end, and (D) large in size and triangular in shape. Bar: $100 \mu \mathrm{m}$.
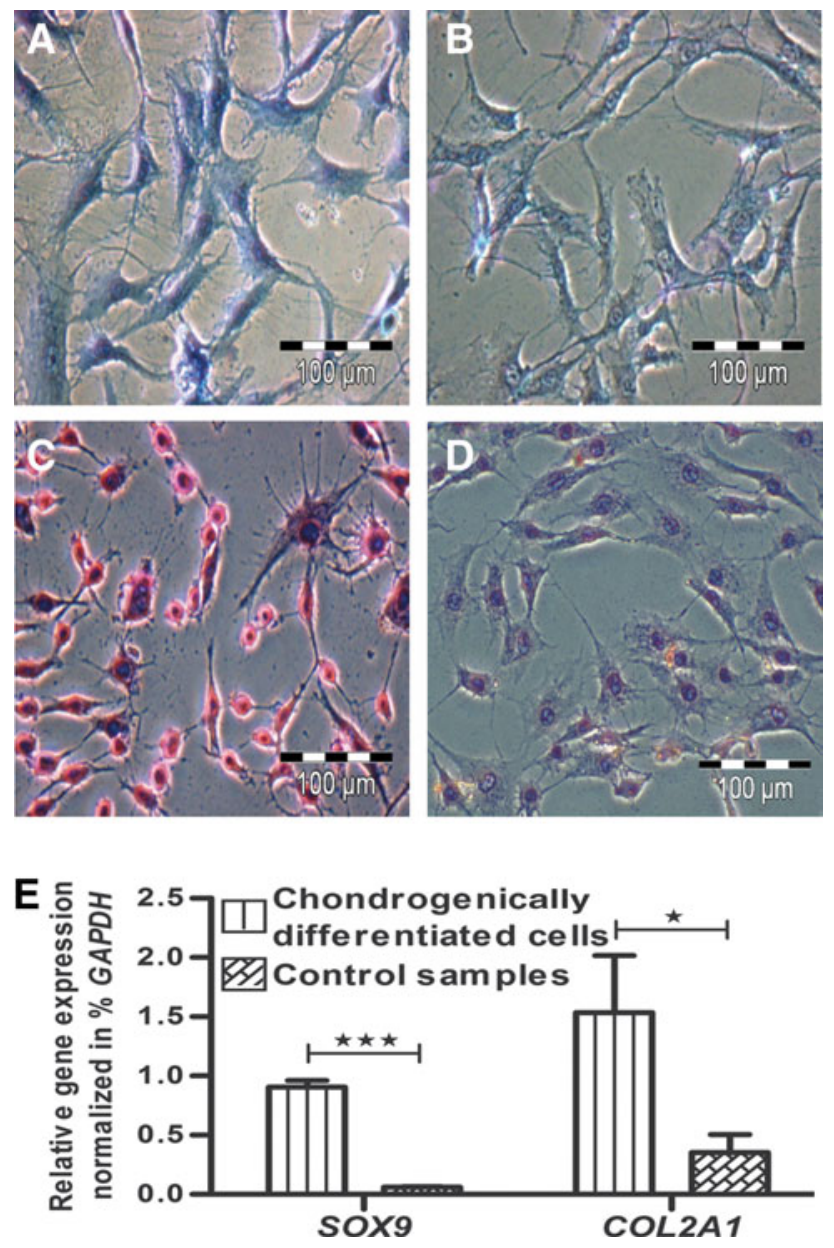

FIG. 7. The released cells from chondrogenically induced pellets were positive for (A) alcian blue and (C) collagen type II staining, while the control samples were negative for (B) alcian blue and (D) collagen type II staining. (E) On the gene level, they showed significant expression for chondrogenic-specific makers like SOX9 and COL2A1 as compared to control samples. Bar: $100 \mu \mathrm{m}$.

ber of released cells. Cells were morphologically normal and proliferated in subculture. Since 120-min incubation did not result in more released cells, 90 min was selected as the appropriate incubation time.

After further optimization of the protocol (centrifugation steps, cell attachment times) for the separation of released cells and ECM from each other, about $2.5 \times 10^{5}$ viable cells/ pellet were released. The next question was whether the enzymatic cocktail affected cell physiology. It has been reported that $\mathrm{CaCl}_{2}$, at least in serum-free media, maintains the chondrogenic phenotype in monolayer and keeps the cells in suspension culture. ${ }^{34}$ However, the viable, chondrogenic cells showed different morphologies. One reason may be a nonuniform nutrient supply to single cells or cell aggregates inside high-density pellet cultures. In this context, we also did not ignore the variable rate of diffusion for TGF $\beta 3$ and enzymes for chondrogenesis and pellet digestion, respectively. It also seems possible that the chondrogenic capacity of the primary MSC varied. Anyway, based on cartilage proteoglycan and collagen type II presentation and gene 


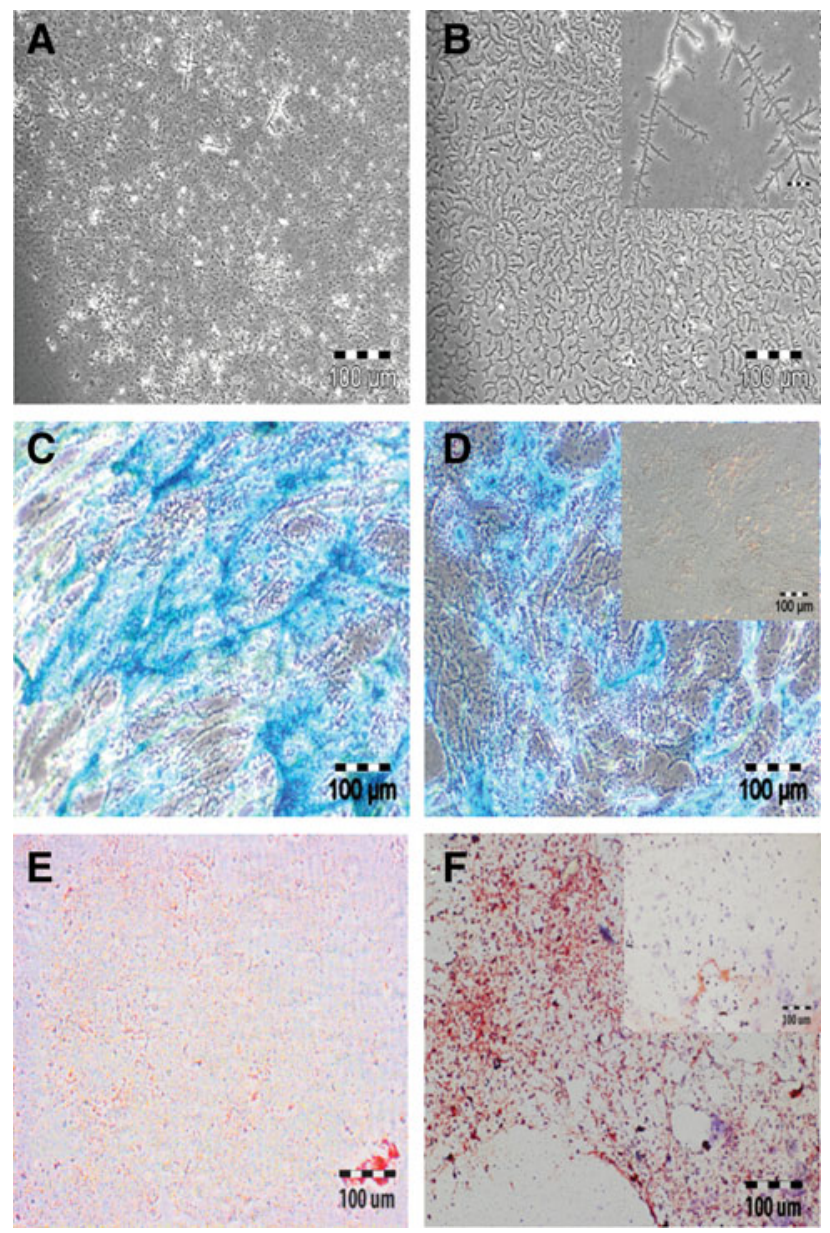

FIG. 8. On morphological evaluation, ECM showed two prominent forms, (A) particle-like appearance and (B) small membrane-like structures (inset is a higher resolution image, bar: $20 \mu \mathrm{m}$ ). The particle-like structures of ECM were (C) positive for alcian blue and (E) marginally positive for collagen type II staining. The membrane-like structures of ECM were equally positive for both (D) alcian blue and (F) collagen type II staining. Insets (D, F): ECM from control samples. Bar: $100 \mu \mathrm{m}$.

expression of COL2A1 and SOX9, released cells had a chondrogenic phenotype. ${ }^{35}$ Not showing here, we observed an extensive proliferation with beginning dedifferentiation towards a less differentiated phenotype, when seeding the cells in MSC culture medium. Therefore, we added the chondrogenic stimulus TGF $\beta 3$ to the culture medium to maintain the chondrogenic phenotype and noticed that most of the cells did not lose their morphological specificity.

Besides the cell fraction, the ECM fraction was isolated, enriched, and preliminarily investigated. Purified ECM not only plays a stimulating role in chondrogenic cell aggregation, ${ }^{36}$ but it is also interesting for therapeutic approaches. For instance, it has been shown that the components of ECM play a curative role in cartilage repair. ${ }^{37-39}$ Additionally, their roles as growth and differentiation factors and cell-recruiting molecules are known and constitute an important research topic. Hyaluronan acid is clinically applied in situ to recruit MSC to cartilage defect sites and to promote cartilage differentiation. ${ }^{10,19}$ This established protocol will play a substantial role in providing purified chondrogenic cells and ECM for future regenerative application.

\section{Conclusion}

The 3D high-density pellet culture is considered a standard culture model for its entrapped chondrogenically differentiated cells. We present a protocol for the reproducible isolation of a defined number of viable, chondrogenically differentiated MSC from this culture. Simple steps, including enzymatic digestion, mechanical homogenization, selective adherence of viable cells, and removal of the ECM-enriched supernatants, result in two fractions consisting of purified chondrogenically differentiated cells and enriched cartilage ECM components. Perhaps this may not seem highly important on the first view. However, for the very high number of groups working on MSC, chondrogenic differentiation, and cartilage repair, our protocol delivers purified chondrogenic MSC and enriched ECM not only for research and development, but also for regenerative therapies. The protocol may also provide a basis for MSC isolation from other matrixfree or matrix-based chondrogenic 3D cartilage cultures.

\section{Acknowledgments}

We gratefully thank Barbara Walewska (Tissue Engineering Laboratory, Charité-Universitätsmedizin Berlin) for excellent technical assistance. The study was supported by the Investment Bank Berlin (IBB) and European Regional Development Fund (grant 10147246), and the Bundesministerium für Bildung und Forschung (grant BCRT 0315848A).

\section{Author Disclosure Statement}

M.S. is a shareholder of CellServe Ltd. (Berlin, Germany) and BioRetis Ltd. (Berlin, Germany) and works as a consultant for BioTissue Technologies Ltd. (Freiburg, Germany), which develops tissue transplants for the regeneration of bone and cartilage. The product activities of the companies are not related to the scientific topics presented here. M.U., H.H., S.S., and J.R. indicate no potential conflicts of interest. All authors disclose any financial and personal relationship with people or organizations that could inappropriately influence this scientifically oriented in vitro study. Therefore, no competing financial interests exist.

\section{References}

1. Pearle AD, Warren RF, Rodeo SA. Basic science of articular cartilage and osteoarthritis. Clin Sports Med. 2005;24:1-12.

2. Tetteh ES, Bajaj S, Ghodadra NS. Basic science and surgical treatment options for articular cartilage injuries of the knee. J Orthop Sports Phys Ther. 2012;42:243-253.

3. Bhosale AM, Richardson JB. Articular cartilage: structure, injuries and review of management. Br Med Bull. 2008;87: 77-95.

4. Temenoff JS, Mikos AG. Review: tissue engineering for regeneration of articular cartilage. Biomaterials. 2000;21: 431-440.

5. Seed SM, Dunican KC, Lynch AM. Osteoarthritis: a review of treatment options. Geriatrics. 2009;64:20-29.

6. Swift A. Osteoarthritis 1: physiology, risk factors and causes of pain. Nurs Times. 2012;108:12-15.

7. Chiang H, Jiang CC. Repair of articular cartilage defects: review and perspectives. J Formos Med Assoc. 2009;108:87-101. 
8. Brittberg M, Lindahl A, Nilsson A, et al. Treatment of deep cartilage defects in the knee with autologous chondrocyte transplantation. N Engl J Med. 1994;331:889-895.

9. Meyer U, Wiesmann HP, Libera J, et al. Cartilage defect regeneration by ex vivo engineered autologous microtissuepreliminary results. In Vivo. 2012;26:251-257.

10. Ringe J, Burmester GR, Sittinger M. Regenerative medicine in rheumatic disease-progress in tissue engineering. Nat Rev Rheumatol. 2012;8:493-498.

11. Loeser RF. Aging and osteoarthritis: the role of chondrocyte senescence and aging changes in the cartilage matrix. Osteoarthritis Cartilage. 2009;17:971-979.

12. Martin JA, Brown T, Heiner A, Buckwalter JA. Posttraumatic osteoarthritis: the role of accelerated chondrocyte senescence. Biorheology. 2004;41:479-491.

13. Tang QO, Carasco CF, Gamie Z, et al. Preclinical and clinical data for the use of mesenchymal stem cells in articular cartilage tissue engineering. Expert Opin Biol Ther. 2012;12: 1361-1382.

14. Barbero A, Ploegert S, Heberer M, Martin I. Plasticity of clonal populations of dedifferentiated adult human articular chondrocytes. Arthritis Rheum. 2003;48:1315-1325.

15. Pittenger MF, Mackay AM, Beck SC, et al. Multilineage potential of adult human mesenchymal stem cells. Science. 1999;284:143-147.

16. Dominici M, Le Blanc K, Mueller I, et al. Minimal criteria for defining multipotent mesenchymal stromal cells. The International Society for Cellular Therapy position statement. Cytotherapy. 2006;8:315-317.

17. Jorgensen C, Noel D. Mesenchymal stem cells in osteoarticular diseases. Regen Med. 2011;6:44-51.

18. Benthien JP, Behrens P. The treatment of chondral and osteochondral defects of the knee with autologous matrix-induced chondrogenesis (AMIC): method description and recent developments. Knee Surg Sports Traumatol Arthrosc. 2011;19: 1316-1319.

19. Siclari A, Mascaro G, Gentili C, et al. A cell-free scaffoldbased cartilage repair provides improved function hyalinelike repair at one year. Clin Orthop Relat Res. 2012;470: 910-919.

20. Johnstone B, Hering TM, Caplan AI, et al. In vitro chondrogenesis of bone marrow-derived mesenchymal progenitor cells. Exp Cell Res. 1998;238:265-272.

21. Eyre DR, Weis MA, Wu JJ. Articular cartilage collagen: an irreplaceable framework? Eur Cell Mater. 2006;12:57-63.

22. Qi WN, Scully SP. Type II collagen modulates the composition of extracellular matrix synthesized by articular chondrocytes. J Orthop Res. 2003;21:282-289.

23. Roughley PJ. The structure and function of cartilage proteoglycans. Eur Cell Mater. 2006;12:92-101.

24. Mrugala D, Dossat N, Ringe J, et al. Gene expression profile of multipotent mesenchymal stromal cells: identification of pathways common to TGFbeta3/BMP2-induced chondrogenesis. Cloning Stem Cells. 2009;11:61-76.

25. Ringe J, Sittinger M. Tissue engineering in the rheumatic diseases. Arthritis Res Ther. 2009;11:211.

26. Pfaffl MW. A new mathematical model for relative quantification in real-time RT-PCR. Nucleic Acids Res. 2001;29:e45.
27. Wu Q, Li C, Li C, et al. Purification and characterization of a novel collagenase from Bacillus pumilus Col-J. Appl Biochem Biotechnol. 2010;160:129-139.

28. Petrova D, Derekova A, Vlahov S. Purification and properties of individual collagenases from Streptomyces sp. strain 3B. Folia Microbiol (Praha). 2006;51:93-98.

29. Mohal JS, Tailor HD, Khan WS. Sources of adult mesenchymal stem cells and their applicability for musculoskeletal applications. Curr Stem Cell Res Ther. 2012;7:103-109.

30. Hayman DM, Blumberg TJ, Scott CC, Athanasiou KA. The effects of isolation on chondrocyte gene expression. Tissue Eng. 2006;12:2573-2581.

31. Wolf F, Candrian C, Wendt D, et al. Cartilage tissue engineering using pre-aggregated human articular chondrocytes. Eur Cell Mater. 2008;16:92-99.

32. Dehne T, Karlsson C, Ringe J, et al. Chondrogenic differentiation potential of osteoarthritic chondrocytes and their possible use in matrix-associated autologous chondrocyte transplantation. Arthritis Res Ther. 2009;11:R133.

33. Endres M, Neumann K, Schroder SE, et al. Human polymerbased cartilage grafts for the regeneration of articular cartilage defects. Tissue Cell. 2007;39:293-301.

34. Gigout A, Jolicoeur M, Buschmann MD. Low calcium levels in serum-free media maintain chondrocyte phenotype in monolayer culture and reduce chondrocyte aggregation in suspension culture. Osteoarthritis Cartilage. 2005;13: 1012-1024.

35. Lefebvre V, Smits P. Transcriptional control of chondrocyte fate and differentiation. Birth Defects Res C Embryo Today. 2005;75:200-212.

36. Gigout A, Jolicoeur M, Nelea M, et al. Chondrocyte aggregation in suspension culture is GFOGER-GPP- and beta1 integrin-dependent. J Biol Chem. 2008;283:31522-31530.

37. Henson FM, Getgood AM, Caborn DM, et al. Effect of a solution of hyaluronic acid-chondroitin sulfate- $\mathrm{N}$-acetyl glucosamine on the repair response of cartilage to single-impact load damage. Am J Vet Res. 2012;73:306-312.

38. Marti-Bonmati L, Sanz-Requena R, Rodrigo JL, et al. Glucosamine sulfate effect on the degenerated patellar cartilage: preliminary findings by pharmacokinetic magnetic resonance modeling. Eur Radiol. 2009;19:1512-1518.

39. Taniguchi S, Ryu J, Seki M, et al. Long-term oral administration of glucosamine or chondroitin sulfate reduces destruction of cartilage and up-regulation of MMP-3 mRNA in a model of spontaneous osteoarthritis in Hartley guinea pigs. J Orthop Res. 2012;30:673-678.

Address correspondence to: Jochen Ringe, PhD

Tissue Engineering Laboratory

Department of Rheumatology

Charité-Universitätsmedizin Berlin

Charitéplatz 1

10117 Berlin

Germany

E-mail: jochen.ringe@charite.de 